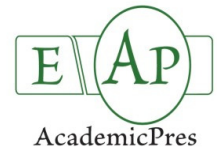

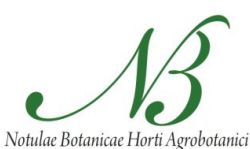

Clij-Napoca

\title{
Extraction and Characterization of Phenolic Compounds from Rose Hip (Rosa canina L.) Using Liquid Chromatography Coupled with Electrospray Ionization - Mass Spectrometry
}

\author{
Andreea STĂNILĂ, Zorița DIACONEASA, Ioana ROMAN, Nicuşor SIMA, \\ Dănuț MĂNIUȚIU, Alin ROMAN, Rodica SIMA*
}

University of Agricultural Sciences andVeterinaryMedicine,3-5Mănăs̆tur,Chij-Napoca, 400372,Romania; andreeastanila@usamvcluj.ro;zoritassonta@usamvchij.ro; ioanaroman@usamvchirro;nicusorsima@usamvchivro;dan.maniutiu@usamvchij.r; raoul.roman@gmail.com;rodicasima@usamvchj.ro(*orrespondingauthor)

\begin{abstract}
Wild berry are a rich of natural compounds which provide them high antioxidant potential. The compounds which provide them these proprieties are known to be vitamins, flavonoids, anthocyanins and phenolic acids. The aim of this study was to extract, identify and characterize bioactive compounds from rose hip (Rosa canina L.) currently found in Romania. A qualitative high-performance liquid chromatography coupled with electrospray ionization mass spectrometric (ESI-MS) detection in positive ion mode has been used to identify phenolic compounds from rose hip crude extract. The chromatograms revealed the presence of a large number of compounds (19), identified and grouped as phenolic acids and flavones/ols, flavan3-ols and also anthocyanins. Based on obtained results these berries can be highly recommended as part of our diet. Also this finding represents a contribution to the chemical characterization of phenolic profile of rose hip.
\end{abstract}

Keywords: anthocyanins, flavonoids, HPLC, phenolic acids, rose hip

\section{Introduction}

The genus Rosa L. (Rosaceae) covers more than 100 wild species and thousands of cultivars, which are widespread and grow in the north part of Europe, Asia, Middle East and North America (Rehder, 1940; Gu et al., 2003). Rosa canina L. (rose hip) is an important berry for food industry due to its rich chemical composition. The small berries are an important source of colour, flavours and bioactive compounds with potential health benefits (Hvattum, 2002; Wu et. al., 2005; He et al., 2010; Jodee et al., 2011; Rugină et al., 2012; Tayefi-Nasrabadi et al., 2012; Widen et al., 2012; Dulf et al., 2013; Yang et al., 2015). Rose hip contains compounds with antioxidant potential such as ascorbate, ß-carotene, glutathione, a-tocopherol, anthocyanins and other phenolics (Ercisli, 2007; Nojavan et al., 2008; Tozzi et al., 2008; Tumbas et al., 2012; Czyzowska et al., 2015). So far, fruits of Rosa canina L. (Rosaceae), rose hips, are known for their high content of vitamin $\mathrm{C}$ and for their great flavour. Rosa canina L. grows naturally in Romania and, as reported previously, fruit and flavoured teas are very popular in many European countries (Pękal et al., 2011). Rose hip can be consumed in both raw and dried state, being used in the herbal tea for flavour and a natural dose of vitamin $\mathrm{C}$. The chemical composition of rose hip has been very rarely evaluated in comparing with other berries containing similar compounds. The polyphenols contained by rose hip are a large group of secondary metabolites. They are widely distributed in vegetables and berries ranging from simple molecules, such as phenolic acids, to complex molecules with numerous phenolic groups, e.g. acylated flavonoid glycosides, proanthocyanidins or tannins. Polyphenols occur primarily in conjugated form, linked to sugars moieties, and to other compounds, such as carboxylic and organic acids, amines, lipids and even to other polyphenols (Bravo, 1998; Guimarães et al., 2013).

Rose hip consumption has been associated with preventive and therapeutic proprieties against a wide range of degenerative diseases, including the inflammatory arthritis disorder, rheumatism, gastrointestinal disorders or cancer (Larsen et al., 2003; Rein et al., 2004; Christensen et al., 2008; Fujii et al., 2009; Andersson et al., 2012). In a recent study Widen et al. (2012) has evaluated erythrocyte antioxidant protection of rose hips. They have investigated the degree of amelioration of oxidative damage in an erythrocyte in vitro bioassay by comparing the effects of a reducing agent on erythrocytes alone with the effect on erythrocytes pretreated with berry extracts. The obtained results revealed that the maximum protection against oxidative stress, $59.44 \%$, was achieved when incubating the cells with the first eluted meta-phosphoric extract. Removal of ascorbic acid from this extract increased the protection against oxidative stress to $67.9 \%$. These results clearly indicate that rose hips contain a

Received: 08 July 2015. Received in revised form: 13 Sept 2015. Accepted: 15 Sept 2015. Published online: 10 Dec 2015. 
350

promising level of clinically relevant antioxidant protection (Widen et al., 2012). Another published study reports that the rose hip fractions rich in flavonoid inhibit cell proliferation in HeLa, MCF7 and HT-29 cell lines (Tumbas et al., 2012). The potential health benefits of rose hips are due to the polyphenolic compounds found in these berries that are mainly flavonoid, phenolic acids and anthocyanins.

Since these classes of compounds are normally found as complex molecules in natural sources, several techniques have been developed for their separation and identification: mass spectrometry (MS) is the most used with several techniques, such as electrospray ionization mass spectrometry (ESI-MS), liquid chromatography coupled with mass spectrometry (LC/MS), matrix-assisted laser desorption/ionization time-of-flight mass spectrometry (MALDI-TOF MS) coupled with mass spectrometric (MS/MS), high performance thin layer chromatography (HPTLC) and also nuclear magnetic resonance NMR (Nawwar et al., 1994; Wang et al., 1999; Reed et al., 2005; Mandal et al., 2008; Ferrari et al., 2011; Savage et al., 2011; Hingse et al., 2014; Ali et al., 2015; Jin et al., 2015). Being one of the most common fruit used in our country as herbal tea, the proposal of this work was to characterize their chemical profile. Therefore, the objective of the present study was to identify individual phenolic compounds in rosehip using the HPLC-ESI-MS.

\section{Materials and Methods}

\section{Plantmaterial}

Fully ripened rose hips (Rosa canina L.) from spontaneous flora of Transylvania (Cluj, Feleac) were harvested during the months of September and October 2011. Samples were randomly collected from several plants and the form and variety of biotype to be analysed was taxonomically classified after a preliminary botanical identification. The identified sample was Rosa canina var. lutetiana f. flexibilis. Rose hips without calyxes were washed with water and kept in a freezer at $-20{ }^{\circ} \mathrm{C}$ prior to the analysis.

\section{Chemicals}

All solvents, reagents and standards used to perform the experiments were of analytical grade. Methanol, formic acid (purity 98-100\%) and hydrochloric acid 32\% were provided by Sigma-Aldrich (Darmstadt, Germany). Anthocyanins standards, cyanidin-3-O-glucoside chloride, cyanidin-3-O-galactoside (purity 90\%), cyanidin-3-arabinoside (purity 97\%), cyanidin-3O-glucoside (purity 95\%) and cyanidin (purity 95\%) were purchased from Polyphenols (Norway) while phenolic acids as gallic acid, protocatecuic acid, chlorogenic acid, catechin, caffeic acid, vanilic acid, rutin, ellagic acid, p-coumaric acid, ferulic acid, myricetin, tilirosid, quercetin and kaempferol were all purchased from Sigma-Aldrich, Darmstadt, Germany.

\section{Extraction of polyphenolic compoundsfrom rose hip}

The method used to obtain crude extract rich in phenolic compounds was done according to previous studies with minor modifications (Cuevas-Rodriguez et al., 2010; Rugină et al., 2012). Berries samples, $1 \mathrm{~g}$ each, were grounded using an ultraturax (Miccra D-9 KT Digitronic, Germany) and weighed, followed by addition of $10 \mathrm{ml}$ of acidified methanol $(0.3 \% \mathrm{HCl}$ $(\mathrm{v} / \mathrm{v}))$. The extraction process was repeated until the samples were colourless. The acidic condition was created in order to prevent anthocyanins from degradation. The obtained extracts were filtered through multiple layers of cotton and concentrated at $35^{\circ} \mathrm{C}$ under reduced pressure (Rotavapor R-124, Buchi, Switzerland). Thereafter, it was dissolved in a known amount of acidified water, filtered through $0.45 \mu \mathrm{m}$ Millipore filter and analyzed by liquid chromatography.

\section{HPLC-DAD/-ESI-MS identification of anthocyanins, flavonol glycosides and phenolic acids}

Samples were analyzed on an Agilent 1200 system equipped with a binary pump delivery system LC-20 AT (Prominence), a degasser DGU-20 A3 (Prominence), a diode array SPD-M20 A and an UV-VIS detector (DAD). Volumes of $10 \mu \mathrm{l}$ were

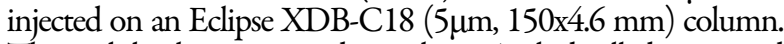
The mobile phase consisted in: solvent A - bidistilled water and $0.1 \%$ formic, B - acetonitrile. The gradient elution system started with $10 \%$ B for 9 min. The percent of B increased to $12 \%$ at $17 \mathrm{~min}$ and continued up to $25 \% \mathrm{~B}$ at $30 \mathrm{~min}$, between minute 30 and 50 the percentage of $\mathrm{B}$ being $90 \%$. DAD recorded full spectra. In-line MS data were recorded by directing the LC flow to a Quadrupole 6110 mass spectrometer (Agilent Technologies, Chelmsford, MA) equipped with an ESI probe. Flow rate was $0.5 \mathrm{ml} / \mathrm{min}$ and column temperature was maintained at $25^{\circ} \mathrm{C}$. The chromatograms were monitored at 280, 340 and $520 \mathrm{~nm}$, respectively. The compounds identification and peak assignments were done based on their retention times, UV-VIS spectra and also compared with standards and published data. As a confirmation the samples were analyzed by HPLC-ESI-MS. The measurements were performed in the positive mode with an ion spray voltage of $3000 \mathrm{~V}$, and a capillary temperature of $350{ }^{\circ} \mathrm{C}$. Data were collected in full scan mode within the range 280 to $1000 \mathrm{~m} / \mathrm{z}$. Identification of anthocyanins, flavonol glycosides and phenolic acids was carried out based on molecular mass determination, masses and occurrence of fragments, elution order and literature data reported previously (Koponen et al., 2007; Adam et al., 2013; Guimarães et al., 2013).

\section{Results and Discussion}

Rose hip (Rosa canina L.) varieties were not extensively studied, due to this fact the present study relieved that they are a rich source of anthocyanins, flavonol glycosides and phenolic acids. The identification of phenolic compounds present in rose hip crude extract was performed by comparing their UV-Vis spectra with published data and available standards, as well, trough HPLCDAD-ESI/MS. A total of 19 different types of phenolic compounds were identified in crude extract. The main classes of phenolic compounds identified were grouped in phenolic acids and flavones/ols, flavan-3-ols and also anthocyanins. HPLC profile of polyphenols was recorded at three wavelengths: $280 \mathrm{~nm}$ for phenolic acids, $340 \mathrm{~nm}$ for flavan-3-ols and $520 \mathrm{~nm}$ for anthocyanins. The obtained chromatograms with each identified peak are showed and discussed below.

\section{Phenolic acids and flavones/ols}

In crude extract of rose hip, hydroxycinnamic acids were the major class of phenolic acids which is in agreement with literature (Hvattum, 2002; Guimarães et al., 2013). Peak assignments of the different identified compounds are presented 


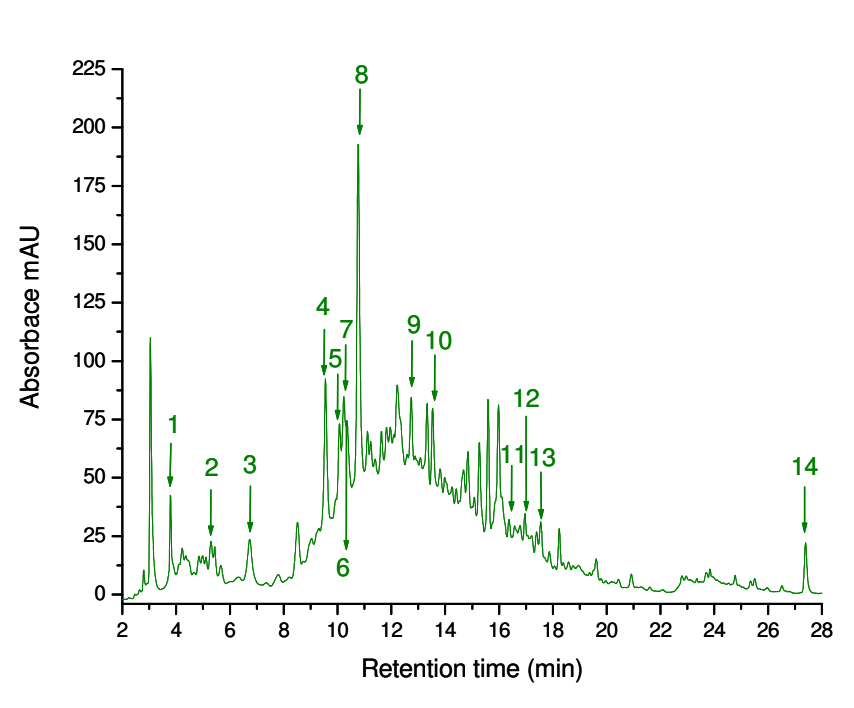

A

Fig. 1. HPLC chromatogram of rose hip crude extract at $280 \mathrm{~nm}$ (A) used for recording phenolic acids and flavones/ols and mass spectrum under peak $14(\mathrm{~B})$ analysed with LC/MS using positive ESI

Table 1. HPLC-MS tentative identification of phenolic acids in rose hip crude extract

\begin{tabular}{|c|c|c|c|c|c|}
\hline $\begin{array}{c}\text { Peak } \\
\text { no }\end{array}$ & $\begin{array}{c}\mathrm{Rt} \\
(\mathrm{min})\end{array}$ & $\begin{array}{l}\lambda \max \\
{[\mathrm{nm}]}\end{array}$ & $\begin{array}{c}\text { Molecular ion } \\
{[\mathrm{M}-\mathrm{H}]+(\mathrm{m} / \mathrm{z})}\end{array}$ & Tentative identification & Identification type \\
\hline 1 & 3.7 & 352 & $435 / 301$ & Quercetin-pentoside & $\mathrm{DAD} / \mathrm{MS}$ \\
\hline 2 & 5.2 & 289 & $451 /(289,153,137)$ & Eriodictyol hexoside & $\mathrm{DAD} / \mathrm{MS}$ \\
\hline 3 & 6.7 & 355 & $479 / 303$ & Quercetin hexuronide & $\mathrm{DAD} / \mathrm{MS}$ \\
\hline 4 & 9.5 & 358 & $463 / 301$ & Quercetin 3-O-glucoside & Standard DAD/MS \\
\hline 5 & 10.0 & 354 & $479 / 301$ & Quercetin glucuronide & $\mathrm{DAD} / \mathrm{MS}$ \\
\hline 6 & 10.2 & 355 & $479 / 301$ & Quercetin hexuronide & $\mathrm{DAD} / \mathrm{MS}$ \\
\hline 7 & 10.4 & 298 & $347,185,163$ & Methyl gallate-hexoxid & $\mathrm{DAD} / \mathrm{MS}$ \\
\hline 8 & 10.7 & 304 & 229 & Resveratrol & $\mathrm{DAD} / \mathrm{MS}$ \\
\hline 9 & 12.7 & 325 & 355,180 & 3-Caffeoylquinic acid & $\mathrm{DAD} / \mathrm{MS}$ \\
\hline 10 & 13.5 & 280 & 595,287 & Kaempferol rhamnosyl-hexoside & $\mathrm{DAD} / \mathrm{MS}$ \\
\hline 11 & 16.3 & 250340 & 566 & Apigenin (+galactoside-arabinoside) & $\mathrm{DAD} / \mathrm{MS}$ \\
\hline 12 & 16.9 & 250363 & 340 & Coumaroylic acid (isomer 3-p) & $\mathrm{DAD} / \mathrm{MS}$ \\
\hline 13 & 17.2 & 348 & 701 & Tilirosid & Standard DAD/MS \\
\hline 14 & 27.7 & 360 & 302 & Quercetin & Standard DAD/MS \\
\hline
\end{tabular}

in Table 1 . The analysed crude extract was characterized by the presence of a large number of phenolic acids and flavones/ols, more specifically 14 individual compounds (Fig. 1).

Quercetin derivates which have $\lambda$ max around 355 and an MS fragment at $\mathrm{m} / \mathrm{z} 301$ were mainly identified in rose hip crude extract (peak 1, 3, 4, 5, 6, 14). Structure, fragmentation, full ESIMS and spectra of quercetin is showed in Fig. 1.

Detected quercetin derivates were assigned to quercetin pentoside ([M-H] at $\mathrm{m} / \mathrm{z} 435)$; peaks 3-6 ([M-H] at $\mathrm{m} / \mathrm{z} 479)$ were tentatively identified as quercetin hexuronide, quercetin 3O-glucoside, quercetin glucuronide and quercetin hexuronide. This identification of quercetin glycosides was done based on process of releasing a $301(\mathrm{~m} / \mathrm{z})$ ion fragment in the MS/MS spectrum.

Other phenolic acids detected in rose hip crude extract were identified as 3-caffeoylquinic acid and coumaroylquinic acid (isomer 3-p) (peak 9, 12) based on the fragmentation patterns described previously by Clifford et al., 2006. Peak $10([\mathrm{M}-\mathrm{H}]$ at $\mathrm{m} / \mathrm{z} 595$ ) was identified as kaempferol rhamnosyl-hexoside.

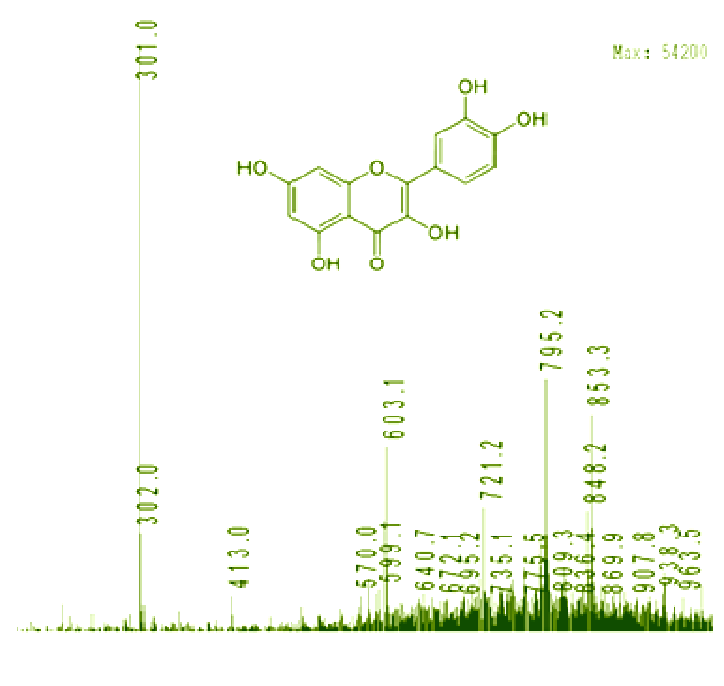

The obtained results are in agreement to available literature (Jin et al., 2015). However, to the best of our knowledge, this is the first report that relieved the presence of resveratrol in the rose hip crude extract (Fig. 1 at $280 \mathrm{~nm}$ ).

\section{Flavan-3-ols}

Catechin (flavan-3-ols) is the most frequent form of flavanols that occurs in plants (Vagiri et al., 2012). The identified flavan-3-ols in rose hip crude extract are catechin and catechin hexoside, their galloyl derivates, according to their comparison with standards, published data and also confirmed by ESI-MS analysis.

The presence of catechin in rose hip has been previously reported (Hvattum, 2002; Guimarães et al., 2013). We identified peaks 1 as catechin with ([M-H] at $\mathrm{m} / \mathrm{z} 290)$. Their derivates were identified as catechin methyl gallate with $([\mathrm{M}-\mathrm{H}]$ at $\mathrm{m} / \mathrm{z} 291)$ and catechin hexoside with ([M-H] at $\mathrm{m} / \mathrm{z}$ 475). The HPLC-ESI-MS fingerprint from the rose hip crude extract is shown in Fig. 2. Peak assignments of the different identified compounds and their MS spectra are shown in Table 2. 


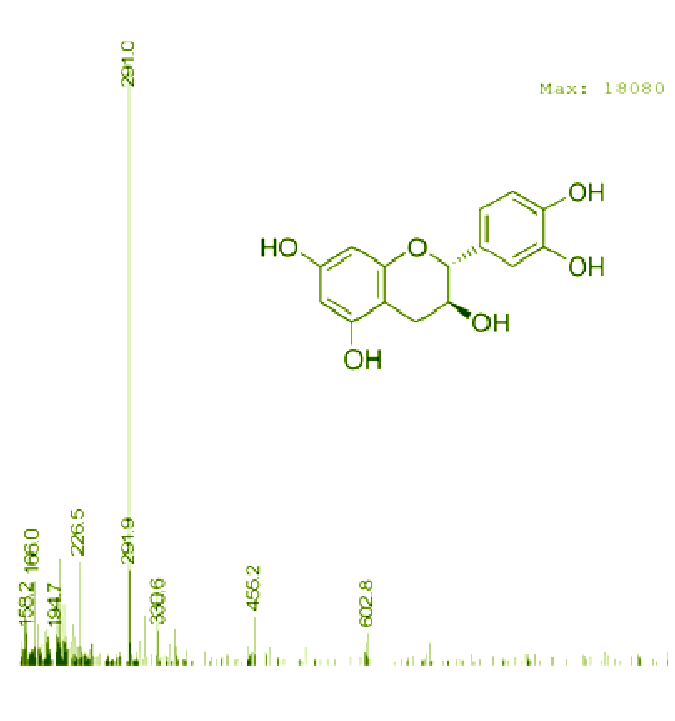

A

B

Fig. 2. HPLC chromatogram of rose hip crude extract at $340 \mathrm{~nm}$ (A) used for recording flavan-3-ols and mass spectrum under peak 1 (B) analysed with LC/MS using positive ESI

Table 2. HPLC-MS tentative identification of flavan-3-ols in rose hip crude extract

\begin{tabular}{cccccc}
\hline $\begin{array}{c}\text { Peak } \\
\text { no }\end{array}$ & $\begin{array}{c}\text { Rt } \\
(\mathrm{min})\end{array}$ & $\begin{array}{c}\lambda \max \\
{[\mathrm{nm}]}\end{array}$ & $\begin{array}{c}\text { Molecular ion } \\
{[\mathrm{M}-\mathrm{H}]+(\mathrm{m} / \mathrm{z})}\end{array}$ & Tentative identification & Identification type \\
\hline 1 & 12.2 & 280 & 290 & Catechin & Dimmer Methyl gallate \\
2 & 13.7 & 278 & 185 & Catechin methyl gallate & DAD/MS \\
3 & 15.2 & 280 & 475 & Catechin hexoside & DAD/MS \\
4 & 15.5 & 280 & 291 & ND & \\
5 & 15.9 & 280 & 436,175 & & \\
\hline
\end{tabular}

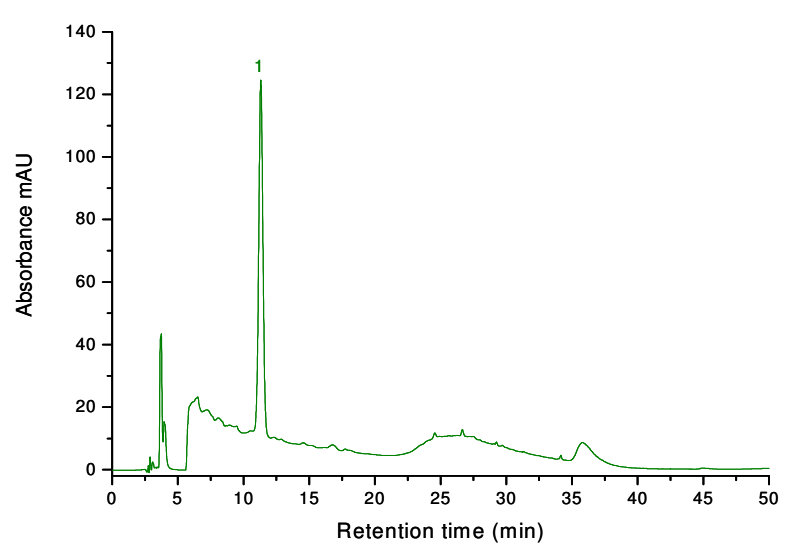

A

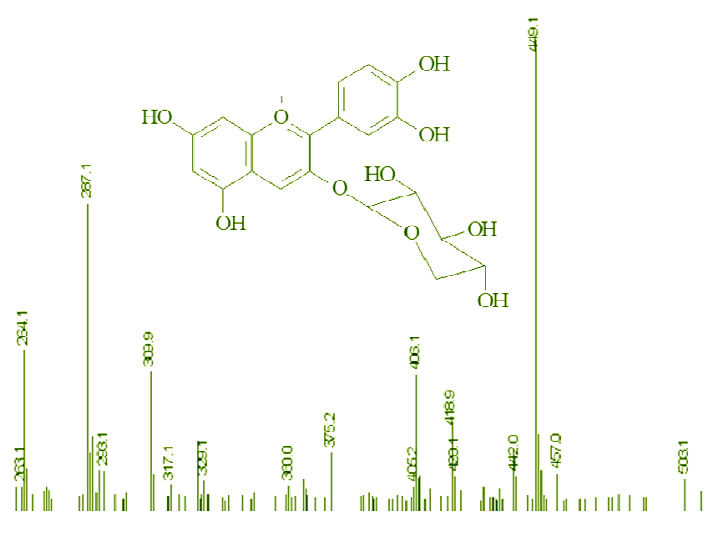

B

Fig. 3. HPLC chromatogram of rose hip crude extract at $520 \mathrm{~nm}(\mathrm{~A})$ used for recording anthocyanins and mass spectrum under peak 1 (B) analysed with LC/MS using positive ESI

Recent performed studies relieved that rose hip contains significant amounts of phenolic acids with antioxidant activity (Roman et al., 2013), the major compounds being catechin, a proanthocyanidin monomer, a proanthocyanidin dimmer, rutin, quercetin galactoside, quercetin glucoside and cyanidin-glucoside
(Widen et al., 2012). The identified compounds in this study are in agreement with published data related to the phenolic compounds in rose hip (Hvattum, 2002; Widen et al., 2012; Guimarães et al., 2013). 
Table 3. HPLC-MS tentative identification of anthocyanins in rose hip crude extract

\begin{tabular}{cccccc}
\hline $\begin{array}{c}\text { Peak } \\
\text { no }\end{array}$ & $\begin{array}{c}\text { Rt } \\
(\mathrm{min})\end{array}$ & $\begin{array}{c}\lambda \max \\
{[\mathrm{nm}]}\end{array}$ & $\begin{array}{c}\text { Molecular ion } \\
{[\mathrm{M}-\mathrm{H}]+(\mathrm{m} / \mathrm{z})}\end{array}$ & Tentative identification & Identification type \\
\hline 1 & 11.3 & 516 & 449,287 & Cyanidin-3-O- glucoside & Standard DAD/MS \\
\hline
\end{tabular}

\section{Anthocyanins}

The anthocyanins profile obtained for rose hip crude extract consists in only one compound (Fig. 3). The chemical characteristics regarding the identity and mass spectrum of the anthocyanin found in the analysed sample is presented in Table 3.

\section{Conclusions}

The present study provides for the first time information regarding the chemical composition of Rosa canina var. lutetiana f. flexibilis. In this study, 19 individual types of phenolic compounds were identified such as anthocyanins, flavonol glycosides and phenolic acids. Moreover, these results represent an important contribution to the chemical profile characterization of phenolic compounds using HPLC-ESI-MS and diode-array detection from rose hip crude extract. However, further studies are required in order to evaluate the percentage of each compound and their antioxidant potential.

\section{Acknowledgments}

This work was supported by the Romanian Ministry of Education and Scientific Research, CNCSIS - UEFISCDI, PNII-RU-PD-2012-3 - 0055, grant nr. 47/30.04.2013.

\section{References}

Adam ME, Novy SK, Yeshitila AT, Suryadi Ii, Lien HH, Yi-HJ (2013). Extraction, identification and quantitative HPLC analysis of flavonoids from sarang semut (Myrmecodia pendan). Industrial Crops and Products 41:392-396.

Ali F, Ranneh Y, Ismail A, Esa NM (2015). Identification of phenolic compounds in polyphenols-rich extract of Malaysian cocoa powder using the HPLC-UV-ESI-MS/MS and probing their antioxidant properties.Journal of Food Science and Technology 52:2103-2111.

Andersson U, Berger K, Högberg A, Landin-Olsson M, Holm C (2012). Effects of rose hip intake on risk markers of type 2 diabetes and cardiovascular disease: a randomized, double-blind, cross-over investigation in obese persons. European Journal of Clinical Nutrition 66:585-590.

Bravo L (1998). Polyphenols: chemistry, dietary sources, metabolism, and nutritional significance. Nutrition Reviews 56:317-333.

Christensen R, Bartels EM, Altman RD, Astrup A, Bliddal H (2008). Does the hip powder of Rosa canina (rosehip) reduce pain in osteoarthritis patients? - a meta-analysis of randomized controlled trials. Osteoarthritis and Cartilage 16:965-972.

Clifford MN, Marks S, Knight S, Nikolai K (2006). Characterization by LC-MSn of Four New Classes of p-Coumaric Acid-Containing Diacyl Chlorogenic Acids in Green Coffee Beans. Journal of Agricultural and Food Chemistry 54:4095-4101.

Cuevas-Rodriguez EO, Yousef GG, Garcia-Saucedo PA, Lopez-Medina J,
Paredes-Lopez O, Lila MA (2010). Characterization of anthocyanins and proanthocyanidins in wild and domesticated Mexican blackberries (Rubus spp.). Journal of Agricultural and Food Chemistry 58:74587464.

Czyzowska A, Klewicka E, Pogorzelski E, Nowak A (2015). Polyphenols, vitamin $\mathrm{C}$ and antioxidant activity in wines from Rosa canina $\mathrm{L}$. and Rosa rugosa Thunb. Journal of Food Composition and Analysis 39:6268.

DulfF, Oroian I, Vodnar D, Socaciu C, Pintea A (2013). Lipid classes and fatty acid regiodistribution in triacylgycerols of seed oils of two Sambucus species (S. nigra L. and S. ebulus L.). Molecules 18:11768-11782.

Ercisli S (2007). Chemical composition of fruits in some rose (Rosa spp.) species. Food Chemistry 104:1379-84.

Ferrari E, Foca G, Vignali M, Tassi L, Ulrici A (2011). Adulteration of the anthocyanin content of red wines: Perspectives for authentication by Fourier Transform-Near InfraRed and 1H NMR spectroscopies. Analytica Chimica Acta 701:139-151.

Fujii T, Saito M (2009). Inhibitory effect of quercetin isolated from rose hip (Rosa canina L.) against melanogenesis by mouse melanoma cells. Bioscience, Biotechnology, and Biochemistry 73:1989-1993.

Gu C, Robertson KR(2003). Rosa L. In: Team FoCe.Ed. Flora of China. St. Louis, MO: Missouri Botanical Garden Press.

Guimarães R, Barros L, Dueñas M, Carvalho AM, Queiroz MJ, SantosBuelga C, Ferreira IC (2013). Characterisation of phenolic compounds in wild fruits from Northeastern Portugal. Food Chemistry 141:37213730.

He J, Giusti MM (2010). Anthocyanins: natural colorants with healthpromoting properties. Annual Review of Food Science and Technology 1:163-187.

Hingse S, Digole S, Annapure U (2014). Method development for simultaneous detection of ferulic acid and vanillin using highperformance thin layer chromatography. Journal of Analytical Science and Technology 5:1-9.

Hvattum E (2002). Determination of phenolic compounds in rose hip (Rosa canina) using liquid chromatography coupled to electrospray ionisation tandem mass spectrometry and diode-array detection. Rapid Communications in Mass Spectrometry 16:655-662.

Jin H, Liu Y, Yang F, Wang J, Fu D, Zhang X, Peng X, Liang X (2015). Characterization of anthocyanins in wild Lycium ruthenicum Murray byHPLC-DAD/QTOF-MS/MS. Analytical Methods 7:4947-4956.

Jodee LJ, Joshua AB, Joseph CS, Giusti MM (2011). Effect of black raspberry (Rubus occidentalis $\mathrm{L}$.) extract variation conditioned by cultivar, production site, and fruit maturity stage on colon cancer cell proliferation. Journal of Agricultural and Food Chemistry 59:16381645.

Koponen JM, Happonen AM, Mattila PH, Törrönen AR (2007). Contents of anthocyanins and ellagitannins in selected foods consumed in Finland. Journal of Agricultural and Food Chemistry 55:1612-1619. 
354

Larsen E, Kharazmi A, Christensen LP, Christensen SB (2003). An antiinflammatory galactolipid from rose hip (Rosa canina) that inhibits chemotaxis of human peripheral blood neutrophils in vitro. Journal of Natural Products 66:994-995.

Mandal SM, Dey S (2008). LC-MALDI-TOF MS-Based Rapid identification of phenolic acids. Journal of Biomolecular Techniques 19:116-121.

Nawwar MAM, Hussein SAM, Merfort I(1994). NMR spectral analysis of polyphenols from Punica granatum. Phytochemistry 36:793-798.

Nojavan S, Khalilian F, Kiaie FM, Rahimi A, Arabanian A, ChalaviS (2008). Extraction and quantitative determination of ascorbic acid during different maturity stages of Rosa canina L. fruit. Journal of Food Composition and Analysis 21:300-305.

Pękal A, Dróżdż P, Biesaga M, Pyrzynska K (2011). Evaluation of the antioxidant properties of fruit and flavoured black teas. European Journal of Nutrition 50:681-688.

Reed JD, Krueger CG, Vestling MM (2005). MALDI-TOF mass spectrometry of oligomeric food polyphenols. Phytochemistry 66:22482263.

Rein E, Kharazmi A, Winther K (2004). A herbal remedy, Hyben Vital (stand. powder of a subspecies of Rosa canina fruits), reduces pain and improves general wellbeing in patients with osteoarthritis - a doubleblind, placebo-controlled, randomised trial. Phytomedicine 11:383-391.

Rehder A (1940). Manual of cultivated trees and shrubs hardy in North America. New York: Macmillan.

Roman I, Stănilă A, Stănilă S (2013). Bioactive compounds and antioxidant activity of Rosa canina L. biotypes from spontaneous flora of Transylvania. Chemistry Central Journal 7:73.

Rugină D, Sconța Z, Leopold L, Pintea A, Bunea A, Socaciu C (2012). Antioxidant activities of chokeberry extracts and the cytotoxic action of their anthocyanin fraction on HeLa human cervical tumor cells. Journal of Medicinal Food 15:700-706.
Savage AK, van Duynhoven JP, Tucker G, Daykin CA (2011). Enhanced NMR-based profiling of polyphenols in commercially available grape juices using solid-phase extraction. Magnetic Resonance in Chemistry 49Special issue(S1):S27-S36.

Tayefi-Nasrabadi H, Sadigh-Eteghad S, Aghdam Z (2012). The effects of the hydroalcohol extract of Rosa canina L. fruit on experimentally nephrolithiasic Wistar rats. Phytotherapy Research 26:78-85.

Tozzi R, MulinacciN, Storlikken K, Pasquali I, Vincieri FF, Bettini R(2008). Supercritical extraction of carotenoids from Rosa canina L. hips and their formulation with beta-cyclodextrin. AAPS PharmSciTech 9:693-700.

Tumbas VT, Canadanovic-Brunet JM, Cetojevic-Simin DD, Cetkovic GS, Ethilas SM, Gille L (2012). Effect of rosehip (Rosa canina L.) phytochemicals on stable free radicals and human cancer cells. Journal of the Science of Food and Agriculture 92:1273-1281.

Vagiri M, Ekholm A, Andersson SC, Johansson E, Rumpunen K (2012). An optimized method for analysis of phenolic compounds in buds, leaves, and fruits of black currant (Ribes nigrum L.). Journal of Agricultural and Food Chemistry 60:10501-10510.

WangJ, Sporns P (1999). Analysis of anthocyanins in red wine and fruit juice using MALDI-MS. Journal of Agricultural and Food Chemistry 47:2009-2015.

Widen C, Ekholm A, Coleman M, Renvert S, Rumpunen K (2012). Erythrocyte antioxidant protection of rose hips (Rosa spp.). Oxidative Medicine and CellularLongevity doi:10.1155/2012/621579

Wu X, Prior RL (2005). Systematic identification and characterization of anthocyanins by HPLC-ESI-MS/MS in common foods in the United States: fruits and berries. Journal of Agricultural Food Chemistry 53:2589-2599.

Yang B, Kortesniemi M (2015). Clinical evidence on potential health benefits of berries. Current Opinion in Food Science 2:36-42. 